\title{
Swinburne University of Technology
}

\section{Carol-Anne Croker and Mark Carthew}

\author{
'The Boat that Rocked': Restoring the creative: a new journey for dual \\ sector universities
}

\begin{abstract}
Global research connections are an increasingly important focus for all universities and for governments seeking to position themselves as providers of high quality research, as partners in education and practice. Value is now recognised for research proposals and projects that enhance international cooperation and collaboration between individual researchers, and the opportunities for exploring uncharted research terrain and pedagogy within the creative writing discipline is encouraged under a raft of new funding schemes and through additional openings within previously limited and targeted schemes. Australian creative writing programs now have an imperative to expand our existing national and international collaborative research linkages and include areas such as children's writing and other hitherto underrepresented areas within our course offerings to ensure and, where necessary, establish valued course and research cultures - and vibrant national and international linkages in this area of creative arts and writing. Creative writing and the creative arts generally are no longer positioned at the margins of the higher education system. Increasingly our practice and expertise is valued as central to Australian economic and cultural development as the foundation for a 21st-century knowledge-based economy.

Keywords: creative writing; dual-sector universities; children and young adult writing
\end{abstract}

\section{Introduction}

This is a conceptual paper outlining an agenda for future research into the position of creative arts (writing) courses in the Australian higher education sector. It articulates a vision that may be Melbourne-centric yet can be viewed as nationally applicable. It is not intended to be empirical in nature, and situates the discussion in the geographic region familiar to the author/practitioners' education and industry knowledge.

In 2010 a nautical analogy of stormy seas and of charting new courses for creative writing programs seems timely as changes for policy, pedagogy and practice can be considered a 'perfect storm' developing on the seas of the Australian higher education sector. This paper investigates how creative writing programs can stay buoyant and at the forefront of higher education challenges for the new century, and build on the progress already made by the AAWP in ensuring that creative writing research and scholarship remains valued and intrinsic to future higher education initiatives fostering Australia as a competitive and vibrant outward-looking research community. By restoring the position of 'creative' and 'creativity' as something of critical importance for the future direction of Australian higher education discourse, we can chart a new path for dual sector institutions while maintaining the valued role of single sector institutions.

\section{The boat that rocked}

In the 2009 movie The Boat that Rocked, Bill Nighy's Quentin and his crew remained afloat to celebrate the joy of contemporary music by transmission through radio bandwidths outside the 
usual broadcast parameters of the time. The captain and crew thought 'outside the square' in order to keep full sail ahead. Similarly in Australia our universities, together with their research institutes, learned academies, scholars and academics, need to ensure that they are adaptable and ready to meet unforeseen changes in the (policy) weather generated by stormy (political and economic) seas rising on the tide of the global education market.

In the 21st century we, the crew members of the 'good ship Academe', need to prepare our lifeboats, train our crews and nurture our sense of adventure in readiness for the exploration of new horizons. We (the senior, mid, early career researchers and, of course, the research 'deck hands' - the PhD candidates and post docs) need to chart new courses and reach new destinations. No longer can we chart the known disciplinary courses; we must acknowledge the imperative for inter-disciplinarity wrought by changing technologies and modes of knowledge production.

As reported by Cunningham and Gascoigne (2008), the former prime minister, Kevin Rudd, in his closing speech at the 2020 Summit noted that, in Australia, we need to 'put ... to bed the false dichotomy between the arts and sciences'. In Venturous Australia: the Review of the National Innovation System, this dichotomy is problematised even further: 'Australia's innovation policy needs to acknowledge and incorporate the role of the creative and liberal arts' (Rudd, cited Cutler 2008: 48). The 'new' destinations and formerly unknown territories have now been mapped by the politicians and bureaucrats in Venturous Australia. As Luke Jaaniste, Research Fellow in Queensland University of Technology's Creative Industries Faculty, states:

This response holds the perspective that the creative arts and broader humanities (HASS sector) can drive, produce, apply and diffuse innovation, in different but equally useful ways to the STEM sector ... it does not adequately follow this through in the substance of its discussions and recommendations. (Jaaniste 2008)

Richard Florida's (2002) recognition of creative cities and creative classes as globally significant contributors to the economic growth posits that political stability for countries and regions can be assured through this open market approach to education and training. For Australian higher education policy and innovation policy agendas the imperative becomes the discovery of niche markets within the global market. Many competitive grant funding allocations are now tied to forming alliances and collaborations with newly emerging research nations. These 'new destinations', particularly collaborations with the 'emerging' research nations (India, China and in South America), have re-invigorated the education and research discourse with an increased interdisciplinary focus for creative arts disciplines underpinned by this rhetoric of globalisation.

With the higher education sector increasingly positioned as product-driven industry with export-earning capacity, there has been a radical altering of education policy and institutional strategic planning to take advantage of scarce government funds from the increasingly competitive national grants schemes, the Australian Research Council and the National Health and Medical Research Council. Monash University's Bob Birrell and T Fred Smith dispute the peak university bodies' claims that education is the country's third largest export earner. They assert that the figure is misleading, with up to half of the purported figure of $\$ 15$ billion coming from overseas students' earnings onshore here in Australia, and as such should not be classified as export earnings, taxation source possibly, but not export dollars (Birrell \& Smith 2010).

Given these discrepancies, universities remain unsure how to position themselves in the internationalised marketplace. Indeed, the 'good ship Academe' is beset by gale force winds and mountainous seas, made even more tumultuous by the 2010 federal election, and minority government with both major parties' advocacy of a larger domestic student body and aspirations for an increased enrolment from lower socio-economic student cohorts. Yet, with funding still insecure for 2011 onwards, many universities (including some dual-sector universities) are over-enrolling their government subsidised places and facing fiscal pressure to increase full fee paying local places to allow for the cross-subsidy of core (and underresourced) local education provision, in the same way that full fee paying overseas student enrolments have been viewed as a convenient short-term revenue stream:

From a financial perspective, this policy created huge success. Educational services became one of Australia's top exports ... But from an academic viewpoint, problems soon entered the system ... Bottom feeders entered the 
market, as usually happens when financial gain becomes the central motivator for international higher education. (Altbach \& Welch 2010)

We suggest that as university administrations follow expansionist policies, the student demand for 'popular' courses such as those offered in the creative arts will be of central importance in playing the ledger-balancing game. Should universities look more closely at leveraging increased funding from the federal government? Should all universities 'play the same game'? Given the precarious nature of the minority government, the answers to these questions could have drastic pedagogical and quality provision impacts on the Australian higher education sector.

This paper argues that these shifts in educational policy and government funding demand a broadening of the education that is provided and indeed marketed to both the domestic and international students. It is the contention of this paper that the HCA (Humanities and Creative Arts) cluster disciplines are well suited to capitalise on the development of niche education markets, both at home and abroad. Now that PhDs by artefact and exegesis in creative arts disciplines have become an increasingly valued and academically rigorous research higher degree, potential higher degree candidates have a broader and more inter-disciplinary career path into the academy. With the predicted shortage of qualified academic staff due to the age profile of the existing academic workforce, it is now the perfect opportunity for universities to actively market these doctorates both domestically and internationally. This is increasingly important now that the international staff profile and international student enrolments are counted towards institutional quality assessment metrics, such as International University ranking schemes, and particularly the QS world university ranking metrics.

\section{Setting sail}

Let's examine the international and global education agenda as outlined in a recent policy document from the Australian federal government's Department of Innovation, Industry, Science and Research, Powering Ideas: An Innovation Agenda for the Twenty First Century. Value is now to be recognised for research proposals and projects that enhance international cooperation and collaboration between individual researchers and discipline clusters with likeminded global partners. These global partners correspond with the rapidly growing economies of Asia where there are existing models for research collaboration in place under the Science Division's Co-operative Research Centres, whose charter is:

To deliver significant economic, environmental and social benefits to Australia by supporting end-user driven research partnerships between publicly funded researchers and end-users to address clearly articulated, major challenges that require medium to long term collaborative efforts. (Carr 2009)

The ramification of this shift in focus for collaborative and international research goes a long way towards challenging the 'great cultural divide' between the realm of the conceptual, the intellectual, on the one hand and the artisan and craftsman on the other. Universities must reconfigure their own disciplinary structures and search out new research synergies. We are encouraged to launch cross- and inter-disciplinary research both to enhance academic credibility for the discipline and to ensure direct practical applications within our industry sector and communities.

For scholars trained in both TAFE sector education and higher education, the future looks navigable. By looking at the nexus between 'soft' innovation and the creative industries it is possible to foreground the skills-based training and industry-transferable skills demonstrated within creative arts disciplines. For many scholars in Victorian universities this addresses the 'thin blue line' (Carthew 2010) that divides creative writing practice into professional writing as taught in the TAFE sector and creative writing as taught in the universities. By bridging the two sectors with distinct academic pathways and credit recognition between institutions and courses, particularly diplomas in professional writing and editing (TAFE) and bachelor level degrees or graduate certificates in creative writing (universities), Australia can ensure a smooth transition for non-traditional university students. With increased employer demand for better industry-education articulation for graduate students, universities offering their students capstone units and industry-based learning programs are recognised by many potential students as more relevant and accessible for non-traditional university entrants. Through these increased 
industry-education linkages, the authors of this paper assert that at their home campus situated in a lower SES outer suburban location, there appears a greater willingness for lower socioeconomic student cohorts to shoulder a HECS (higher education contribution scheme) student loan as a personal investment in their future careers.

Our university campus is also the 'home' for our off-campus Open University Australia (OUA) administration, and our campus student enrolment from this mode of enrolment has increased exponentially over the last three years, and resulted in our OUA staff awarded an Australian Learning and Teaching Award for Teaching Quality in 2010. We also offer the country's only fully off-campus Graduate Certificate program, expanding access for students unable to participate in on campus study for reasons such as employment commitments, carer duties or geographic isolation, including overseas students and isolated regional inter and intra-state students. By enabling educational access for non-traditional students, thus countering geographic factors concerns that limit participation in university education, creative arts (writing) programs allow flexible and asynchronous study modes to be marketed to potential students, and enable the university to meet the Bradley report target of increased participation for students from non-traditional pathways.

What remains a problem is the direct lack of structured articulation between the TAFE sector qualifications and course content and that of the universities. Looking at the authors' experience in Victoria, currently there is no common course content among the universities' creative writing programs, nor do they sit in any particular research/disciplinary cluster, reflecting the former institutional affiliations in the pre-Dawkins era (the 1980s), when the sector was unified with the amalgamation of universities and colleges of advanced education (Moses 2004).

It is the contention of the authors that the content and subject nomenclature within creative writing programs has more relevance to institutional history than as an effort to unify the discipline consistent with HCA disciplines across the range of research fields. Creative writing is offered as part of cultural studies, English, creative arts, communications, humanities and of course, the social sciences (which remain notionally within the HCA cluster of disciplines).

With each positioning comes specific disciplinary pedagogy and practices, privileging some subject offerings over others. Looking at the research intensive universities' subject offerings (with the notable exception of the University of Adelaide), there appears a privileging of certain pedagogies that demand, at doctoral level for example, a heavier weighting on the exegetical component than the creative. At the newer universities, the weighting between the two components can vary significantly.

With the few dual sector institutions offering both TAFE (Technical and Further Education) and university programs, there again exists a division in content and focus for writing programs: those deemed 'professional writing and editing', and those deemed 'creative writing'. Neither is focused on traditional literary analysis or cultural analysis; and both claim in their marketing material to offer students 'industry-level' training in writing. While this can be attributed to the historical divisions within the sector or to the perception of niche marketing of courses, we note that there is increased policy discussion and governance focus on the smooth articulation between the TAFE and university sectors, under pathways initiatives. This has caused much consternation, with some vice chancellors publicly questioning the suitability of TAFE institutions to ensure quality university level qualifications, and the TAFE directors arguing that universities are becoming increasingly responsive to industry-based learning, formerly their educational terrain.

In the Victorian TAFE sector, the professional writing syllabus is determined by industry-based relevance for student employment. Unit offerings closely reflect the publishing industry skills sets: novel writing, magazine and short story writing, screen and script writing, children's and adolescent writing, nonfiction writing and professional editing.

With university policy increasingly industry-focused, and capstone units marketed as pathways between study and employment, it seems anachronistic that some creative writing programs in the university sector still do not give equal prominence to industry-based training (professional writing and editing) along with exegetical/academic writing and creative writing research. Thus there exists an apparent 'inflexible' mindset on the part of creative arts administrators and faculty, which results in a false dichotomy between theory and practice. To move beyond this divide and to answer broader educational imperatives for Australian higher education students, our creative writing programs must chart the new courses emerging during the coming 'perfect storm' of global educational change: 
This is an exciting time for us early-career researchers with the newly opened rite of passage currently granted by government funding agencies through the recognition of the contribution to society of the Arts and Humanities disciplines, where practice-led (and practice-based) research is flourishing. But are our dual-sector institutions' good ship Academe up to speed and ready to launch on the current high tide? We fear not. (Croker \& Carthew 2009)

A skilled workforce is aspired to by all OECD nations in the current quest to build 'knowledge economies' more adaptable to technological and scientific change. In 2001, the Federal Labor Opposition positioned the term 'knowledge nation' as the central discourse determining Australia's future wealth and influence, echoing the research by the then shadow Federal Science Minister, Barry Jones:

The Knowledge Nation is not just about universities and lab coats, it is just as much about schools, apprenticeships and the factory floor. It is about the way we do business; address our environmental needs; respond to our social problems ... In the Knowledge Nation, education will have to start earlier in life, continue throughout life, and be of a higher quality than ever before. (Jones, cited Kingston 2003)

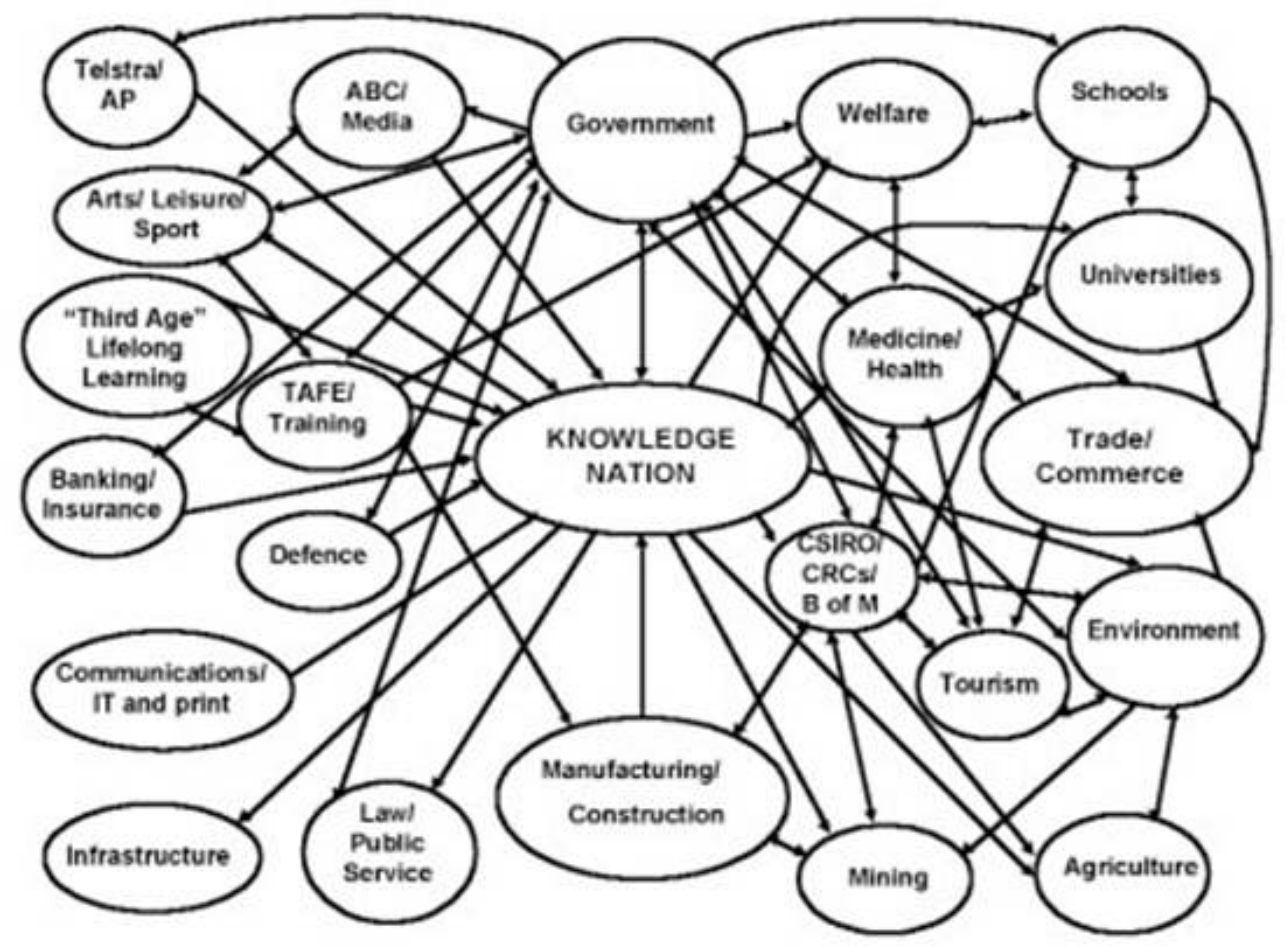

FIGURE 1: The complex interactions between the elements of the Knowledge Nation (Knowledge Nation Taskforce 2001: 9)

And while Barry Jones' diagram (above) was much ridiculed at the time, the central concepts and ideas are still powering the discourse today. At the time one defender of the Chifley Centre's Knowledge Nation Taskforce Report was Margo Kingston, columnist with the Sydney Morning Herald (and syndicated in the Age) who suggested:

Its definition of 'knowledge' is surprisingly broad and expansive. The Knowledge Nation isn't just a country committed to learning and research ... Knowledge Nation talks about the disappearing public intellectual, the need to reassert the value of the humanities and the need to rebuild great national institutions like the CSIRO, the National Library and the ABC. (Kingston 2003)

It is this definition of knowledge that is currently the foundation for the innovation agenda; these connections between education, culture, arts, science, technology and industry. And for our education sector the government's current focus remains educating for the 'knowledge nation'. 
However, while it is too early to identify the discovery of a 'new world' order, there are some pleasing prospects for those of us working and educating in the arts and humanities sectors. The OECD's Directorate of Education has, since 2006, been at pains to develop a 'worldwide higher education assessment system', an appropriate set of metrics against which each country's educational institutions and productivity can be measured in terms of world's best practice. From this has emerged the PISA (Program for International Student Assessment), to measure 15 -year-old student achievement against dollars invested by governments. As noted by the Australian newspaper's Higher Education correspondent, Gavin Moodie, 'Australia does very well in PISA, performing consistently in the top group ... It finds that Australia performs significantly higher than would be expected from its spending per student' (Moodie 2007).

In 2007, UNESCO's CERI (Centre for Education, Research and Innovation) Directorate 'identified considerable challenges for the development of internationally comparative measures of higher education learning outcomes and acknowledged that there was no clear roadmap for overcoming these - some compared the situation with when Columbus set sail' (CERI 2007). The Australian university sector is undergoing a rapid paradigm shift to compete on the world stage and have our universities viewed as offering world's best practice in tertiary education. The global visibility of Australian universities on quality ranking scales such as the Shanghai Jao Tong top 500 world universities and the QS World University Ranking system is increasingly important for future funding, which in turn influences prospective students' perception of educational quality and of their potential marketability as graduates to future employers. These reputation indices are measured under the international rankings schemes. Australian universities' allocation of scarce government research dollars is increasingly linked to adherence to quality assurance metrics and hierarchical ranks on such scales: so much so that Australia has now developed TESQA (Tertiary Education Quality and Standards Agency), which replaces AUQA (Australian University Quality Agency), to ensure our tertiary education institutions are able to be directly compared with overseas institutions.

This is indeed a 'new world' for Australian universities where student numbers measured as EFTSL (Equivalent Full Time Student Load) are the prime driver of government institutional funding and the overseas full fee paying student market the necessary revenue stream to crosssubsidise core educational functions.

We need to link two of the Australian government's key policy foci for the coming years, the need to increase funding for higher education provision and the need to increase funding for children's literacy education. The first is necessarily dependent upon the success of the latter. The first requires the reconfiguration of the higher education sector to increase participation by students aged $25-34$ to $40 \%$ by 2020 , and in particular to increase the participation in secondary education or TAFE training participation by 15-24 year olds in the coming decade, particularly increasing access for the socio-economically disadvantaged and other marginalised groups not being targeted by the education sector despite equal opportunity and affirmative action policies, both state and federal, and across institutions:

Within the OECD we are now 9th out of 30 in the proportion of our population aged 25 to 34 years with such qualifications, down from 7 th a decade ago. Twenty-nine per cent of our 25- to 34-year-olds have degreelevel qualifications but in other OECD countries targets of up to 50 per cent have already been set. (Bradley 2008: xi)

To ensure this is possible, Australia must examine its entire education system from early childhood to pre-school, primary school and finally secondary schooling. We cannot expect there to be a readily qualified student cohort to be swept into university-level studies by 2020 without ensuring adequate resourcing and emphasis on literacy and early intervention now. As identified by Bradley, the goal is that:

All qualified individuals will have an entitlement to undertake an undergraduate qualification unlimited in duration or value. This is consistent with the need to broaden the base of higher education qualifications in the population and the need for skills upgrading over the life cycle ... In partnership with schools and other education providers, higher education institutions will work to raise aspirations as well as provide academic mentoring and support. (Bradley 2008: xiv) 


\section{Safe harbours}

As early as August 2008, the then Deputy Prime Minister and Minister for Education, Julia Gillard, identified the need for more government funding for Australia's pre-tertiary education sectors. The report The Case for an Education Revolution in our Schools speaks in terms of equity and individual empowerment. Instead of turning out more and better 'widgets' faster, our education sector needs to enhance its performance graduating literate, educated, adaptable students. Productivity needs to include a focus on equity and access with more students from all walks of life and abilities. We contend that encouraging innovation through creativity will achieve a balanced education system, delivering programs and subjects suited to each individual student's needs and talents. With a balance between the arts and sciences, we can meet the requirements stated in the report:

This commitment recognises the central role that education plays in the economic and social strength of our nation. Education not only drives productivity but also empowers individuals to reach their full potential, and helps overcome disadvantage. Beyond economic growth, education creates social benefits that help build social capital. Societies with a strong commitment to education enjoy higher levels of civic participation, greater social cohesion, lower levels of crime and disadvantage, and a more trusting, equitable and just society. (Gillard \& Rudd 2009: 5)

This rhetoric of enhanced social and cultural capital harks back to the writings of Pierre Bourdieu in the 1970s, yet today the concept is placed at the centre of the discussion with respect to the role played by the arts within society. The creative industries are increasingly linked with economic prosperity, national identity, social maturity and community wellness as articulated by scholars such as Richard Florida, director of the US Martin Prosperity Institute and the Creative Class Exchange, in his books The Rise of the Creative Class, Who's Your City, and The Flight of the Creative Class (Florida 2002, 2005, 2008).

\section{Ports and prizes}

For the purpose of this paper we acknowledge the positioning of Melbourne as a 'City of literature' and designated a 'Creative City'. Creative desire is also evident in other capitals and regional centres where the literary and creative arts regularly provide a sense of focus; however, success for a creative city is in being forward looking, while acknowledging a place in the wider global creativity market. It is this outward focus that positions Melbourne at the heart of Australia's 'Creative Culture' and recognition on the world stage, a move dovetailing with Labor Arts spokesman Peter Garrett's statement that 'The Government, instead of providing top-up funds for the arts, needs to move to a new funding formula which includes indexation to allow the arts sector to flourish into the long term' (Garrett 2010).

In 2007, on the opening night of the Melbourne Writers Festival, Melbourne was named a UNESCO City of Literature (UNESCO 2008). The state and local governments are working to develop the city as a creative hub in literature with the most recent development in 2009, the opening of the Wheeler Centre for Books and Ideas. The goal of the Wheeler Centre is to draw together writers' festivals, literary arts organisations, university faculties and industry groups to work collegially and co-operatively on enhancing the city's global reputation as a leader in literature and books thus enhancing Melbourne's recognition as a global centre for literature. Steven Carroll, Miles Franklin Literary Award winner, said it confirmed Melbourne as the 'cultural centre of Australia': 'Melbourne has over the last century inspired some of the greatest works of Australian literature. There is just something about the place - just think of books by the likes of Hal Porter, George Johnston, Miles Franklin and Helen Garner' (Carroll, cited Steger 2008). Despite his hyperbole, the UNESCO nomination is an honour: the recognition of world's best practice by at least one of Australia's creative arts industries. In noting the award of the City of Literature, Jason Steger reported the then Arts Minister Lynne Kosky as saying that:

The decision was confirmation of the value of a lot of people who have been working in the literature industry - writers and publishers and those who support writing and publishing. It gives confirmation to them not only about the work they've done but the quality and also the importance of their work to our city and why they are a critical component of it. Also what it does is 
celebrate literature as an important art form, and through the centre we will continue to grow that interest and art form. (Steger 2008)

With such momentum it seems logical to the writers of this paper that the creative industries disciplines in our universities are in a prime position to work with all levels of government and industry to forge both national and international collaborations. Those of us already enrolled in higher degree programs within the practice-led or practice-based (artefact and exegesis) doctoral and masters scholarship have the opportunity to demonstrate exactly how academic research and practice can meld seamlessly into the creativity, innovation, cultural capital continuum.

The recent Creative Arts PhD Roundtables in Sydney and Melbourne hosted by the ALTC (Australian Learning and Teaching Council) saw funding provided for ACUADS (Australian Council of University Arts and Design Schools) to investigate creative arts $\mathrm{PhD}$ programs nationally, and compare them with those on offer internationally, to ensure world-level best practice. ATLC also funded a scoping project examining quality in tertiary creative arts research training to develop the 'best practice model' for the higher education sector. Together with the research being pursued by NOMAD and CHASS (particularly the annual summit with the Department of Innovation, Industry and Research, HASS on the Hill), there is consensus that universities and their respective academic staff should actively involve themselves in the exciting opportunities to affirm the alignment between research and practice in the arts.

This is also the perfect site to examine how the Australian federal government's education agenda can work to respond to the Prime Minister and Education Minister's calls to increase children's literacy. By looking specifically at practice-led research disciplines, particularly creative writing, universities have the opportunity to eliminate unnecessary discipline divisions to develop broader inter- and cross-disciplinary research praxis. However, much work is still needed to position children's writing as a valid research site within creative writing doctorates in our universities. There are no discipline-specific constraints to limit the practice in these higher degrees to adult literature, just a tacit privileging of certain genres (adult and 'literary fiction' specifically), over others. The websites of the various universities show that the marketing departments often promote award-winning authors from their creative writing faculties. More often than not they are writers of adult literature who have garnered prestigious awards. Only recently have university writing faculties opened the door for award-winning children's writers to teach in their field of expertise, since creative works can now be recognized as research outputs, and their industry knowledge and experience are highly regarded. The role of children's writing in creative writing courses is of significant interest to a growing body of active practitioners in the genre - aspiring, emerging and experienced - as is expressed regularly on the stages of our national writing festivals and forums.

This interest in children's literature within the creative arts industry is further evidenced by the increasing number of members of organisations such as the Society of Children's Book Writers and Illustrators. SCBWI is an organisation with "more than 22,000 members worldwide, in over 70 regional chapters writing and illustrating in all genres for young readers from board books to young adult (YA) novels, making it the largest children's writing organization in the world' (SCBWI 2010). Another indication of increased interest in this area of creative writing practice is the proliferation of dedicated children's literature blog sites, for example The Book Chook (2010) and publishing industry focused magazines such as Pass It On, Buzz Words, The Reading Stack.

By recognising a growing community of writers, scholars and educators working in children's literature, universities would be in a strong position to integrate their research practice across many HCA disciplines, including creative writing, design, music, theatre and media, as well as complementary disciplines such as education and social sciences. In a topic for future research, the genre of children's and young adult writing would still seem to be 'emerging' rather than acknowledged as an established genre in practice and scholarship.

\section{Docking and de-rigging}

It is now time to audit our creative writing programs. How many offer supervision by experienced and published children's writers of doctoral candidates who are writing children's literature? Given the recent acceptance of creative works as research output by the ERA, one can argue that there needs to be an examination of how these comparatively new doctoral 
awards by artefact and exegesis are examined. The authors would argue that many (though not all) of these PhDs (writing) state that the emphasis is on 'publishability' of the artefact, and at the same time there has been a shift towards the publishability of the exegetical component in academic journals and monographs. Recognizing the importance of both components, it is important that university creative writing faculties employ and develop the academic careers of published professional writers in all genres.

Arguably, adult fiction sits at the top of the writing course pecking order within the academy via an established position of literary prominence and privilege. Some universities still have little or no representation of children's literature in their specific subject studies. The authors argue that this is an indication of a hierarchical divide between children's and adult literature. In a positive sign, it would appear that higher education courses are responding to a broadening range of genre related writing interests. One example is the University of Sunshine Coast, which offers a dedicated Graduate Certificate in Creative Writing for Youth, as well as the subjects 'Creative Writing for Children' and 'Young Adults \& Creative Writing for the Illustrated Book' in its Graduate Diploma and Postgraduate disciplines for 2010. Flinders University is another such example, reflecting value for the children's genre in its course content.

While we acknowledge that this is but one genre that could argue marginalisation, other popular and indeed populist genres could also find a valued academic space within creative writing programs. Perhaps the corollary of this shift from the margin will be a more integrated relationship between the academy and industry.

While a much fuller study of genre spreads across creative writing course content is required for proper analysis, anecdotal evidence from our writing department colleagues at Swinburne certainly indicates that a number of masters and doctoral students show a demonstrable interest in children's and young adult writing. It is also reflected in the practice-led and scholarly discourse linkages in the major writing festivals. An example is the 'CYA Later Alligator Children's and Young Adult Writer's Conference' (2010) associated with the Brisbane Writer's Festival. Metropolitan and regional writing centres around the country also provide evidence of substantial interest in writing for children and young adults.

It is in this context that higher education creative writing disciplines need to reach out to link with the vocational and higher education sector undergraduates and graduates in this field - as well as with the wider industry - or the benefit of such research and practice linkages will remain underdeveloped or unarticulated. Not to do so denies Australia a position in developing international arts-based research collaborations with our like-minded UNESCO cities of literature and others.

Creative writing doctorates, along with other arts-based doctorates, offer a way ahead for research into creative industries by investigating the similarities or differences cultures face in a globalised market. It allows our practitioners to conceptualise and work in an international academic and artistic space.

The potential for innovation, creativity and the synergy between education sector and industry is one viable model for Australia's higher education sector to meet the challenges outlined in the Bradley Report. We must make education accessible, practical and integrated with work/life demands. All disciplines must examine their practice and relevance in contemporary society.

By looking specifically at creative writing disciplines, and children's literature studies in particular, we can now identify the global and trans-national opportunities that exist for linkages across many disciplines (especially with education, early childhood, language development, ESL, linguistics, anthropology, socio-linguistics, musicology, music therapy, speech therapy, library courses). This pragmatism may be the way to attract funding and position research projects as demonstrating social and cultural benefit with community based outcomes.

Certainly the natural linkages between children's writing and language development and conceptual frameworks are obvious as evidenced by the current research and practice being completed in the United Kingdom The various NAWE writers in schools research projects are indicative of the many opportunities for cross-discipline research and linkages with active practitioner methodology. NAWE is a highly appropriate model for uniting all education sectors and the creative industry practitioners working within the creative writing disciplines. It can be argued that the long-term sustainability of a higher degree in creative writing is to offer insights into real life writing practice by strengthening linkages with industry and 
networks. By exploiting academic staff expertise with genre-specificity, universities and their students can ensure privileged research and practice within their own craft allowing for increased opportunity for industry relevance.

Let's hope Melbourne's privileged status as a UNESCO City of Literature stimulates opportunity in all genres of literature including children's and young adults. Hopefully, it represents an opportunity for greater cohesion and planning between the arts and education sectors. The opportunities for exploring unchartered research terrain and pedagogy within the creative writing discipline can take advantage of the 'raft' of research funding opportunities opened up by this new journey. In the 21st century we, the crew members of the 'good ship Academe', have prepared our lifeboats, trained our crews and continue nurture our sense of adventure in readiness for the exploration of new horizons.

\section{List of works cited}

Altbach, Phillip and Anthony Welch 2010 'Australia: The perils of commercialism', University World News 136, 22 August, at http://www.universityworldnews.com/article.php?story=20100820152350449 (accessed 23 August 2010) return to text

Birrell, Bob and T Fred Smith 2010 'Export earnings from the overseas student industry: how much?', Australian Universities' Review 52:1, http://www.aur.org.au/archive/52-01/aur_52-01.pdf (accessed August 2010) return to text

Bradley, Denise 2008 'Review of Australian Higher Education', http://www.deer.gov.au/Higher Education/Review/Pages/ReviewofAustralianHigherEducationReport.aspx (accessed 17 July 2009) return to text

Carr, Kim 2009 'Powering ideas: an innovation agenda for the twenty first century', Department of Innovation, Industry, Science and Research. AGPS: Canberra, at

http://www.innovation.gov.au/innovationreview/Documents/PoweringIdeas_fullreport.pdf (accessed 6 July 2009) return to text

Carthew, Mark 2010 'The blue between: children's writing in the margins', TEXT 14.2, October return to text

Croker, Carol-Anne \& Carthew, Mark 2009 'The Boat that Rocked', Contemporary issues in business and organisations: proceedings of the Faculty of Higher Education Research Symposium, Swinburne University of Technology, Lilydale, Australia, 3 June, 2009,

at http://researchbank.swinburne.edu.au/vital/access/manager/Repository/swin:17537 (accessed August 2010) return to text

Centre for Research and Innovation Governing Board (CERI) 2007 'PISA for Higher Education', OECD Directorate for Education at http://www.pisa.oecd.org/documents/53/0,3343,en_32252351_32235731_38262901_1_1_1_1,00.html (accessed 17 July 2009) return to text

Cunningham, Stuart and Toss Gascoigne (2008) 'Submission to the Review of the National Innovation System', Council for the Humanities Arts and Social Sciences, http://www.chass.org.au/submissions/SUB20080420SC.php (accessed 10 July 2009) return to text

Cutler, Terry 2008 Venturous Australia: building strength in innovation, North Melbourne: Cutler and Company return to text

Florida, Richard 2002 The rise of the creative class and how it is transforming work, leisure. community and everyday life, New York: Basic Books return to text

Garrett, Peter 2010 'Australia's richest literary awards open for entries' (media release: Office of the Minister for Environment Protection, Heritage and The Arts), at http://www.environment.gov.au/minister/garrett/2010/mr20100330.html (accessed 17 May 2010) return to text

Gillard, Julia and Kevin Rudd 2009 'The case for an education revolution in our schools' at http://www.deewr.gov.au/Schooling/Resources/Documents/Publications/QualityEducationRevolutionWEB.pdf (accessed 25 July 2009) return to text

Jaaniste, Luke 2008 'Comments on the review of the National Innovation System (RNIS): Responding to the RNIS Report: Venturous Australia: building Strength in Innovation', QUT Digital Repository, at http://eprints.qut.edu.au/15767/1/15767.pdf (accessed July 2009) return to text

Kingston, Margot 2003 'Front bar. Knowledge Nation', Sydney Morning Herald, 24 November, at http://www.smh.com.au/articles/2003/11/24/1069522520166.html (accessed 17 July 2009) return to text 
Knowledge Nation Taskforce 2001 An agenda for the Knowledge Nation, Canberra: Chifley Research Centre return to text

Moodie, Gavin 2007 'PISA for Higher Education', The Australian, 26 September, at http://blogs.theaustralian.news.com.au/gavinmoodie/index.php/theaustralian/comments/pisa_for_higher_education/ (accessed 17 July 2009) return to text

Moses, Ingrid 2004 'Unified national system or uniform national system? The Australian experience', at http://www.dest.gov.au/NR/rdonlyres/B37486CD-A383-469C-BFE4-

17F0AC985961/5328/UniversityofNewEnglandfurtherinformation.pdf (accessed 17 July 2009) return to text

Society of Children's Book Writers and Illustrators (SCBWI) 2010, 'About SCBWI: Who We Are \& What We Do', at http://www.scbwi.org/Pages.aspx/Who-We-Are---What-We-Do (accessed September 29, 2010) return to text

Steger, Jason 2008 'Melbourne hooks the books' The Age, 20 August at http://www.theage.com.au/national/melbourne-hooks-the-books-20080819-3y9b.html (accessed July 10, 2009) return to text

United Nations Educational, SaCO (UNESCO) 2008 'Melbourne UNESCO City of Literature' (media release), http://portal.unesco.org/en/ev.php-URL_ID=43330\&URL_DO=DO_TOPIC\&URL_SECTION=201.html (accessed 12 October 2009) return to text

Carol-Anne Croker is a PhD student at Swinburne University. Her PhD artefact is a novel, Walking with Madness. Carol-Anne's research interests and experience include women's popular fiction, feminist fiction, higher education policy research particularly in creative art practice and teaching. As part of her doctoral studies she interned at the Melbourne Writer's Festival.

Mark Carthew is also a current Swinburne University PhD candidate and award winning children's author. Mark's PhD artefact is the early childhood anthology Can You Keep a Secret? Timeless rhymes to share and treasure (Random House Australia), illustrated by Jobi Murphy, which has been noted by the Children's Book Council of Australia (CBCA) as a 2009 Notable Book, Early Childhood.

\section{TEXT}

Vol 14 No 2 October 2010

http://www.textjournal.com.au

Editors: Nigel Krauth \& Jen Webb

Text@griffith.edu.au 